Cahiers $d u$ MONDE RUSSE

\section{Cahiers du monde russe}

Russie - Empire russe - Union soviétique et États indépendants

$56 / 4 \mid 2015$

Médiateurs d'empire en Asie centrale (1820-1928)

\title{
Michael S. Gorham, After Newspeak, Language Culture and Politics in Russia from Gorbachev to Putin
}

\section{Amandine Regamey}

\section{(2) OpenEdition}

Édition électronique

URL : http://journals.openedition.org/monderusse/8302

DOI : $10.4000 /$ monderusse. 8302

ISSN : $1777-5388$

Éditeur

Éditions de l'EHESS

\section{Édition imprimée}

Date de publication : 1 octobre 2015

Pagination : 916-919

ISBN : 978-2-7132-2507-9

ISSN : $1252-6576$

\section{Référence électronique}

Amandine Regamey, « Michael S. Gorham, After Newspeak, Language Culture and Politics in Russia from Gorbachev to Putin », Cahiers du monde russe [En ligne], 56/4 | 2015, mis en ligne le 01 octobre 2015, Consulté le 25 septembre 2020. URL : http://journals.openedition.org/monderusse/8302 ; DOI https://doi.org/10.4000/monderusse.8302

Ce document a été généré automatiquement le 25 septembre 2020. 


\title{
Michael S. Gorham, After Newspeak, Language Culture and Politics in Russia from Gorbachev to Putin
}

\author{
Amandine Regamey
}

\section{RÉFÉRENCE}

Michael S. GORHAM, After Newspeak, Language Culture and Politics in Russia from Gorbachev to Putin, Ithaca - London : Cornell University Press, 2014, 234 p.

1 Le livre dresse un tableau des rapports entre langue et politique depuis la perestroïka. Construit de manière chronologique, en six chapitres, il analyse ce que les évolutions linguistiques reflètent des évolutions sociales et politiques, et de quelle manière la « culture de la langue $»^{1}$ a évolué.

2 Si certaines des analyses n'apportent pas d'éclairage fondamentalement nouveau (sur les relations entre Putin et la population à travers l'émission Prjamaja linija par exemple), l'ensemble permet néanmoins de dresser un tableau synthétique des évolutions récentes, et repose sur des études de cas détaillées et des notions clés qui se répondent d'un chapitre et d'une période à l'autre. Ainsi, un des fils conducteurs du livre est la distinction que fait Gorham entre la langue perçue comme un " instrument » des changements (vision allant de Pierre le Grand aux Bolcheviks, puis à V. Putin) et la langue perçue comme une " essence ", l'expression immuable d'une identité russe.

Dans le chapitre consacré à la glasnost', Gorham rappelle que si cette notion existe depuis le $\mathrm{xIX}^{\mathrm{e}}$ siècle, elle n'est pas à l'origine synonyme de liberté d'expression, mais désigne une manière pour l'État de rendre publique son action, de façon à obtenir une participation a minima des citoyens. C'est bien là au début la vision de M. Gorbačev, pour qui la glasnost' n'est pas " synonyme de dire et faire n'importe quoi ». Dans une longue analyse d'une séance du Premier Congrès des députés du peuple de 1989 
(p. 66-74), Gorham montre comment Gorbačev, en posant les règles de prise de parole, empêche l'ancien procureur Telman Glian de dénoncer la manière dont le parti a étouffé les scandales de corruption en son sein. On voit à cette époque émerger de nouvelles formes de débat (Gorbačev rabroue Glian sur le fait « qu'il n'est pas à un débat télévisé ") mais aussi une nouvelle source d'autorité rhétorique, celle des électeurs, dont les députés se font les porte-parole. Cette nouvelle légitimité s'oppose au modèle " top-down » soviétique, dans lequel la parole, qu'elle soit politique ou qu'elle vise simplement un langage correct et châtié, tire son autorité des classiques (du marxisme/ de la littérature russe) et des institutions chargées de les faire respecter, Académie des sciences ou Politburo (chapitre I).

4 Plus loin, dans un dernier chapitre consacré à la " Glasnost 2.0 ", Gorham souligne à quel point les tentatives du président Medvedev de développer des formes de " démocratie électronique " (blogs, vidéos, sites permettant des commentaires, modérés, des usagers) rappellent cette première vision de la glasnost' comme simple publicisation de l'information sur le pouvoir. Face aux nouveaux outils internet, cette politique de "démocratie électronique " prend ses distances avec ceux qui veulent établir un nouveau " cyber-rideau de fer ", ce qui ne l'empêche pas de recourir à des attaques DDos contre les sites d'opposition qui rappellent les brouillages radios à l'époque soviétique. Elle apparaît surtout comme une réponse forcée aux nouvelles formes d'activisme sur internet, comme les projets d'A. Naval'nyj (Rospil) qui créent une sorte de gouvernement parallèle et subversif et que Gorham analyse en détail.

5 Mais revenons au début des années 1990 et au troisième chapitre du livre : Gorham montre qu'au début des années 1990, c'est la définition de la glasnost' comme « liberté de parole ", considérée comme un droit inaliénable, qui l'emporte, mais que cette notion finira par être dévalorisée au cours des années 1990. Effectivement, après la chute de l'URSS, la logique de marché qui se saisit des journaux s'accompagne de changements linguistiques : mots importés (en particulier de l'anglais), usage croissant d'un langage familier. Cet usage du mat est d'autant plus fort qu'il est " validé " par des autorités telles que les linguistes (qui publient des œuvres empreintes d'un certain romantisme pour le mat vu comme une forme d'énergie vitale opposée au pouvoir), mais aussi les écrivains qui en font une marque de distinction littéraire.

6 Trois mots empruntés à l'anglais, imidž, vaučer, killer, traduisent le mieux, selon Gorham, les évolutions politiques et sociales des années 1990 - en même temps qu'ils révèlent une attitude négative par rapport à ces changements. La liberté de parole, telle qu'elle se déploie dans les années 1990, finit par être vue par certains comme de l'anarchie, un phénomène de " non-droit » linguistique ».

7 Cette notion de jazkykovyj bespredel est caractéristique d'une réaction qui touche la Russie dès les années 1990 : la perversion de la langue par les emprunts et la mode est critiquée au nom d'une vision de la langue comme élément "essentiel ", « organique » du peuple, de l'identité, de la nation russe. Se rattachent à cette réaction les tentatives de l'écrivain A. Solženicyn de réintroduire des mots russes disparus, ou les différentes initiatives prises par l'Église orthodoxe, dont Gorham souligne à plusieurs reprises le rôle très actif.

8 Dans les années 2000, des émissions populaires et des médias sont à nouveau consacrés à la correction de la langue et à une expression châtiée, rappelant celles de l'époque soviétique. Les analyses que Gorham développe dans le chapitre IV renvoient en effet au premier chapitre sur les années 1950-1970, où il étudie la notion de " kul'tura reči ", 
cette discipline qui définit les formes correctes de l'accentuation, des variations grammaticales, de l'usage des synonymes et des mots importés. Les linguistes de l'Institut de la langue russe, qui publiaient des conseils concrets dans des journaux spécialisés ou dans la Literaturnaia Gazeta, étaient alors en relation avec les différents " usagers de la langue " par lettre ou par l'intermédiaire d'une hotline téléphonique.

Cinquante ans plus tard, apparaissent à nouveau des manuels, des émissions populaires dans lesquelles les normes sont fixées "d'en haut " par des personnes investies d'autorité (linguistes, spécialistes). Mais cette fois, les supports en sont la télévision, la radio, internet ${ }^{2}$, supports interactifs qui permettent également la participation des locuteurs lambda (sondages éclairs) ; les journalistes s'en font les « porte-parole » face aux spécialistes dans des émissions en direct, comme l'émission " Parlons russe » sur Écho de Moscou que Gorham analyse en détail.

Cette nouvelle offensive autour de la correction de la langue va jusqu'à l'intervention des autorités politiques. Si le Conseil de la langue russe auprès du président, créé en 1995 sous $\mathrm{El}^{\prime} \mathrm{cin}$, avait finalement été fermé faute de financement, l'initiative est reprise avec beaucoup plus de succès par V. Putin.

11 Il pourrait sembler paradoxal de voir en V.Putin un chantre de la correction du langage, lui qui est arrivé au pouvoir en proclamant qu'il allait « buter [les terroristes] jusque dans les chiottes ». (Gorham rappelle d'ailleurs à ce propos que cet emprunt du futur président à l'argot criminel lui a valu une réelle popularité, montrant qu'il était proche du peuple et qu'il n'était pas de ceux qui parlaient pour ne rien dire). Mais dans le même temps, c'est sous la présidence de V. Putin qu'est adopté un programme pour la langue russe doté de financements conséquents, que se crée le site de référence gramota.ru et, enfin, qu'est votée la loi sur la langue russe de 2005, qui vise expressément à limiter les emprunts et le langage familier.

12 Surtout, la langue russe est un des instruments du soft power que V. Putin déploie envers ses voisins. Gorham montre comment les émissions en direct (prjamaja linija) avec V.Putin, mises en scène de la nation où le peuple pose des questions présélectionnées à un tsar bienveillant et efficace, avaient déjà " franchi " les frontières de la Russie au milieu des années 2000, en prenant des appels des russophones des pays de l'ex-URSS, en particulier d'Ukraine et de Crimée. Remettant en avant l'idée de communauté contre la désunion des années 1990, c'est enfin la notion de monde russe "russkij mir ", d'une "russitude » (russkost') qui transcenderait les frontières géographiques et ethniques, qui devient la base de la politique étrangère depuis la présidence de D. Medvedev.

On ne peut bien sûr s'empêcher de penser à l'actualité des thèses de M. Gorham lorsqu'en juin 2014, alors que la guerre a commencé à l'Est de l'Ukraine, Vladimir Putin déclare dans une conférence de presse que la Russie défendra toujours cette partie de la population ukrainienne qui sent un lien « culturel, linguistique indissoluble avec la Russie, qui se sent partie prenante du vaste monde russe $»^{3}$. 


\section{NOTES}

1. Cette notion de language culture comprend à la fois les pratiques linguistiques d'acteurs divers (simples citoyens, élites culturelles, autorités politiques, etc.), quel que soit le niveau de langage dont ils usent, et l'attitude de ceux-ci envers la langue.

2. On retrouve là le souci que Gorham porte, tout au long du livre, aux questions techniques : il insiste sur le fait que le succès de tel ou tel discours sur la langue dépend des technologies de communication qu'il emprunte (journaux spécialisés vs mass medias, revues vs internet), et sur la capacité des spécialistes à utiliser et accéder à ces technologies (p. 18).

3. Conférence de presse du 24 juin 2014, http://ria.ru/world/20140624/1013426007.html

\section{AUTEURS}

\section{AMANDINE REGAMEY}

Paris I 